\title{
Characterising a teaching and learning environment capable of motivating student learning
}

\author{
David Kember • Amber Ho • Celina Hong
}

Received: 20 January 2008/Accepted: 17 April 2008/Published online: 2 December 2009

(C) Springer Science+Business Media B.V. 2009

\begin{abstract}
This study investigated facets of the teaching and learning environment which motivate student learning. Interviews were conducted with 36 students from nine representative undergraduate degree programs in Hong Kong. The interviewees were asked to describe teaching approaches and learning activities typical of their program. They were asked about the effect of these on their motivation. Analysis of the transcripts, using a grounded theory approach, revealed that motivation was enhanced through a teaching and learning environment with eight supportive conditions, namely, establishing relevance, establishing interest, allowing choice of courses, learning activities, teaching for understanding, assessment of learning activities, close teacher-student relationships and sense of belonging between classmates.
\end{abstract}

Keywords Active learning · Higher education · Motivation ·

Teaching and learning environment

\section{Introduction: Nature of motivation in higher education}

This article reports findings from an investigation of the nature of motivation in higher education and the ways in which curriculum design and the nature of the teaching and learning environment can impact upon student motivation. The results reported here are concerned with the latter part of the ambit of the project. We endeavour to make some suggestions to the many teachers who find it hard to motivate their students or complain that students nowadays are less motivated than they used to be. This introduction, though,

D. Kember $(\varangle) \cdot$ A. Ho $\cdot$ C. Hong

University of Hong Kong, 3/F Run Run Shaw Building, Pokfulam Road, Hong Kong e-mail: dkember@hkucc.hku.hk
A. Ho
e-mail: amberhic@hku.hk
C. Hong
e-mail: slhong@hkucc.hku.hk 
draws upon the characterisation of motivation as it is necessary to identify its nature before dealing with how it can be enhanced.

In view of the voluminous literature on motivation, it might be thought that there would be no need to have an empirical study into the nature of motivation in higher education. However, the literature is replete with so many models, often with competing or conflicting claims, that it can be hard to determine which ones to draw upon. Because a substantial part of the literature has been derived from theory, conclusions can be hard to verify. It is particularly hard to select appropriate literature in a higher education context as much of the empirical research has been conducted in the workplace or in schools, and often junior ones.

Therefore, it was decided that an open study would be of more value than a theorydriven one. Given the range of literature, it was likely that findings could be related to some part of it. However, this would serve to identify which strands of the competing literature are most appropriate for higher education.

The characterisation derived from the first part of the study was formulated as a motivational orientation with six facets (Kember et al. 2008). The concept of an orientation was derived from Taylor et al. (1981), who used it to describe students' aims, expectations and attitudes when they embark on a new course of study. The authors described the concept as:

By orientation we mean all those attitudes and aims that express the student's individual relationship with a course and the University. It is the collection of purposes which orientates the student to a course in a particular way. Orientation, unlike the concept of motivation, does not assume any psychological trait or state belonging to the student. It is a quality of the relationship between student and course rather than a quality inherent in the student. (Taylor et al. 1981, p. 3)

Our version of a motivational orientation, illustrated in Fig. 1, contains six facets which are shown as continua. Students enter university at a position on each of the continua. Their position can then shift along the continua influenced by personal circumstances, their social context and their perceptions of the teaching and learning environment. The vertical arrows are intended to show that there are interaction and influence between the facets. Positive positions on a number of facets can influence students to adopt a more positive stance towards other facets. For those with several negative positions, this can negatively influence other aspects.

The overall orientation framework is consistent with social-cognitive models of motivation (Pintrich 2003; Pintrich and Schunk 2002). They represent motivation as a dynamic multi-faceted phenomenon which is influenced by the context. This means that curriculum design and the nature of the teaching and learning environment play a part in the degree of motivation.

The positive poles of the six continua were then given labels of compliance, individual goal setting, sense of belonging, interest, career and university lifestyle. Compliance consists of a threshold up to which students will complete assignments and set study tasks without question. Compliance arises because students become conditioned to doing, or not doing, set work. The conditioning came from parents, teachers and fellow students.

The individual goal setting was consistent with students having personal targets, which were normally expressed in terms of grades or Grade Point Averages (GPAs). There is substantial literature from goal theorists, of which a major part has dealt with the classification of goals. The earlier literature contrasted performance and mastery goals (e.g. Ames 1992), although alternative terms and variations in definitions are common. 
Fig. 1 Motivational orientation framework for university students (Adapted from Kember et al. 2008)

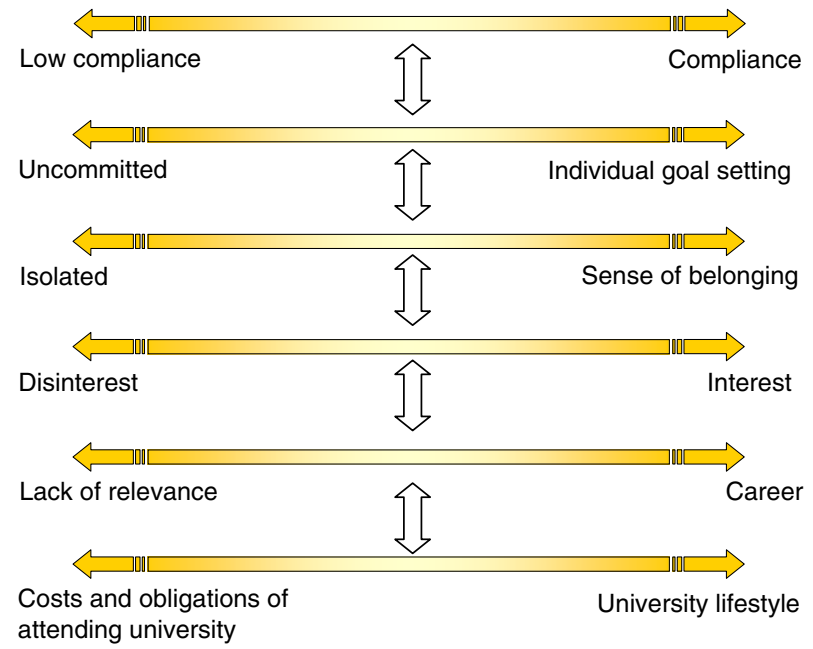

The major distinction is that performance goals involve comparison with other students, while mastery is a self-referenced goal of achieving competence. More recent work (e.g. Elliot and McGregor 2001) has added approach and avoidance foci as an additional dimension to the performance and mastery goals, thus forming a four-category classification system.

In the original formulations of achievement motivation in Western psychology texts, it is described as an individual competitive drive (Biggs 1987). In our study, there was little evidence of goals referenced against others in a competitive sense. The personal goal setting dimension therefore appears to differ from this traditionally defined individual form of competitive achievement motivation in this context. It is not presently clear whether this was a cultural phenomenon and whether competitive goals might appear to be more common in other contexts.

Sense of belonging was a social form of motivation which boosted motivation when there were strong interpersonal links between students in a class. The inclusion of both individual goal setting and sense of belonging resolves a division in the literature between achievement motive as an individual or social drive. Western definitions had defined achievement motive as an individual competitive drive but, in Confucian-heritage countries, achievement motive was seen in reference to the family and society (Hsu 1981; Salili 1996; Yang and Yu 1988; Yu 1974, 1996). Our data suggested that students possessed individual goals, as well as enjoying the benefits of social forms of motivation, if a sense of belonging was established.

The interest facet was reasonably consistent with classic formulations of intrinsic motivation involving interest in the subject matter itself. In professional courses, the scope was somewhat broader, as establishing the relevance of concepts and theories to the future profession or career was shown to be a powerful motivating force.

The career facet differed markedly from formulations of extrinsic motivation as opposite to, or competing with, intrinsic motivation. In our framework, the career facet is a positive motivational force which can and does co-exist with interest; the two can mutually reinforce each other. The career facet is more consistent with the learning orientations formulated by Beaty et al. (2005). They included a vocational orientation with intrinsic and extrinsic sub-categories. The latter was distinguished by students aiming to obtain a qualification which would lead to a job. The intrinsic vocational orientation was defined by 
students seeking training which would equip them well for their future careers, which is more consistent with the career facet of our orientation framework.

The university lifestyle facet deals with motivation through the social life that universities provide. Offset against this were the costs and obligations which arise as a result of enrolling at university. Students performed a form of cost-benefit analysis to see whether attendance was justifiable (Kember 1995).

\section{Method}

The large majority of students entering undergraduate degrees in Hong Kong universities come from Hong Kong and commence their degrees shortly after completing secondary school. Entry to the seven universities funded by the University Grants Committee of Hong Kong (UGC) is restricted to about $17 \%$ per age group (University Grants Committee of Hong Kong 2003). The main factor in selection is the results of the external A level examinations taken at the conclusion of secondary education. In terms of entry to UGCfunded undergraduate degrees, Hong Kong still has an elite education system. Undergraduate students in Hong Kong can be likened to 'traditional' undergraduate students in the West before the advent of mass higher education diversified the intake to universities.

Ways of motivating or de-motivating student learning were investigated through open semi-structured individual interviews. Students were selected from nine undergraduate degree programs offered by three universities in Hong Kong. The three universities were representative of the three types of university in Hong Kong: research-intensive, former polytechnic and former liberal arts college. The programs were then selected to be typical of the university and to provide a range of disciplines as wide and representative as could be managed with a sample of nine. The programs selected are shown in Table 1.

Students who were in the final year of their 3-year undergraduate degree were individually interviewed. This enabled them to reflect on their 3 years of tertiary education. For the part of the interview relevant to this article, semi-structured questions were used to ask the interviewees to describe typical approaches to teaching used in their program, the types of assignments that they were set and the learning activities in which they engaged. They were also asked how these learning experiences affected their motivation. Open questioning techniques were used to allow interviewees to focus on what seemed important to them. Occasionally, students were prompted to seek depth of insights and ascertain the motivational impact of the teaching and learning environments that the students described. The interviews were conducted in Cantonese and full English transcripts were produced. Sample interview questions are as follows:

- How would you describe your experience of higher education?

- Were there any critical incidents which happened during your study in higher education?

Table 1 Programs selected in the three types of university in Hong Kong

\begin{tabular}{lll}
\hline Research intensive & Former polytechnic & Former liberal arts college \\
\hline Medicine & Health sciences & Science \\
Science & Engineering & Communication \\
Social science & Hotel management & Business \\
\hline
\end{tabular}


- How is your course structured?

- What are the best/worst features of the course that you take?

- What are the forms/methods of teaching adopted in your course?

- What are the forms/methods of assessment adopted in your course?

- How would you describe your relationship with the teaching staff?

- How would you describe your relationship with your peers?

The sample was restricted to nine programs, with four students from each program being interviewed. This meant that an insightful view of each program could be obtained. It also meant that it was possible to obtain some degree of verification of the interviewees' accounts by cross-comparison of the four interviews for each program. In each case, the level of consistency was quite high. The students had reasonably common perceptions of the prevailing teaching and learning environment in their programs.

Analysis used a grounded theory approach (Glaser and Strauss 1967; Lincoln and Guber 1985) involving looking for common themes. One member of the research team initially read through the transcripts several times while making marginal notes of aspects of the teaching and learning environment which appeared to be conducive to motivating or demotivating student learning. The transcripts were read as a whole in order so to gain comprehensive insight into each program. The other two members of the team then examined the initial coding for verification against the sense of the interviews. They then proceeded to apply the coding more systematically using the NVivo Qualitative Data Analysis Program (Version 1.3) [Computer software] (2000).

Once this had been completed, it was then possible to sort the transcripts according to the main identified themes. This made it possible to examine each of the main themes for sub-categories. Once identified, these were also coded with NVivo to produce a hierarchical coding structure. This facilitated the identification of quotations typical of the themes and sub-themes. The final level of analysis occurred during the writing.

All of the 36 interviewees participated in the study on a voluntary basis. At the start of the interviews, the purpose of the project and the use to be made of the data was explained to them. They were then asked to sign a consent form. Anonymity of interviewees is maintained in any reporting.

\section{Findings and discussion}

When the transcripts were analysed in terms of the main themes reported as being conducive to motivating student learning, eight main categories or themes emerged. In each case, there was a corresponding de-motivating element. The complementarity between motivating and de-motivating facets of a teaching and learning environment is seen as providing a degree of validating support for the analysis.

Taken together, the eight themes of motivating elements can be seen as characterising a teaching and learning environment conducive to motivating student learning. It appeared necessary to pay attention to all eight elements in order to provide a teaching and learning environment conducive to motivating students. The eight elements are listed below:

- Establishing interest

- Allowing choice of courses

- Establishing relevance

- Learning activities

- Teaching for understanding 
- Assessment of learning activities

- Close teacher-student relationships

- Sense of belonging between classmates.

In the next eight sections, the eight facets of the teaching and learning environment will be considered and illustrated by typical quotations. The eight elements of a motivational teaching and learning environment were derived from the complete set of 36 interviews. Two cases are used to illustrate the eight supportive conditions for motivating student learning: one student who was from the business discipline and was studying in the former liberal arts college; and a student from chemistry in the research-intensive university. These two cases represent a professional degree from which students normally proceed to a career in business, and an applied science career for which graduates enter a wide variety of fields of employment. Quotations from the business student are indicated by (BUSS), while those from the chemistry student by (CHEM). Reporting the two cases in detail, rather than drawing upon quotations from all 36 interviews, seemed to provide a more comprehensive overview of an environment and validate conclusions about the interaction of elements within the environment.

Most of the quotations are from one student from chemistry or business. There is a small number of quotations from the other three students interviewed from each program, with these providing particular insights into a motivating element. Quotations other than those from the principal cases have a code number (e.g. CHEM3). The other three transcripts were also used to verify the substance of the comments included as quotations. In fact, there was a high level of consistency between the main themes emerging from the four interview transcripts for each of the two programs.

\section{Establishing interest}

One of the themes which came through strongly in terms of motivation was interest. Of the 36 interviewees, 28 mentioned interest as an element in their motivation: "Interest is most important. If you are not interested in chemistry, doing labs will be very toilsome for you" (CHEM). The level of interest seemed to be partially an expression of individual preferences. There were individual differences between students, expressed as preferences for different types of subjects. Students' choice of which courses to study at school had been influenced by these preferences. Their reaction to studying the subject at school influenced their application to a particular program. Too many interviewees decided that they did not wish to continue studying their school subjects and chose something different, most commonly a professional award. The chemistry student was one of a minority who expressed an interest in the same subject studied at school, mainly because the experimental work was the main focus of the program:

Actually chemistry requires hard memorization too. Before HKCEE, I disliked chemistry. To me, it was in between physics and biology. I often felt that biology required plain rote learning; physics involved a lot of calculations, whereas chemistry was like a mixture of the above two, requiring one to rote learn and to calculate as well. Actually I disliked chemistry but, when I reached Form 6, doing experiments was fun. (CHEM)

The other aspect of the level of interest was that it was partly a function of the nature of the teaching and learning environment. Whether or not students were interested in a subject was dependent upon the curriculum design, the nature of teaching and the way in which 
content was taught. For the chemistry student, interest was developed through the experiments. However, to have this effect, the experiments must have been reasonably well designed. This suggests that the experiments in organic chemistry referred to below by the chemistry student must have been well designed. Students in some other programs said that they found their experiments tedious:

In labs, I'm able to see changes and I know what I'm doing. During lectures, I'm able to recall what I have done in my experiment (better memorisation so-to-speak). In addition, the ability to do well in my study has also increased my interest. Even though I do not achieve good results every time, it is fun to conduct experiments in organic chemistry. Even though I may have to work for a few hours (quite tiring), I'm able to understand and learn a lot from it. (CHEM)

Another important factor in establishing interest was related to the degree of relevance discussed in more detail below. A common complaint was excessive teaching of abstract theory. Students found it more interesting if the application of the theory could be shown. One of the other chemistry interviewees found that the most interesting teaching was that which related chemistry to everyday life.

In this study, the large majority of the interviewees displayed career motivation in conjunction with intrinsic interest. Students required a course to be both interesting and career relevant. Establishing relevance to the profession was helpful in motivating student learning in professional courses: "One of my interests on which I have spent most of my time is to get myself equipped. Thus, this course is fully fulfilling my interest" (BUSS). The student has a career goal in mind; so courses which will equip him for this future are seen as interesting. He has shown great interest in working in the business field and running his own business since he was young. His courses can capture his interest if he perceives them as making a contribution to readying him for his goal: "I would like to enter the business sector. I have liked it since I was a child. I am longing to run a business" (BUSS). This career motivation, which might be perceived as extrinsic, is certainly not incompatible with intrinsic interest. In subjects in which teachers managed to capture his interest, he worked hard. If interest was not aroused, work effort was minimised: "If you are interested in it, you will be willing to spend more time on the subject. If you are not interested, you will try to get it done as soon as possible" (BUSS).

\section{Allowing choice of courses}

Interest is partly a function of individual preferences and partly a function of the quality of the teaching and curriculum design. The chances of students being interested can be increased by allowing a choice of courses, because different students have different interests.

The business student had made a specific program choice when leaving secondary school to go to university. His interest was to learn more about finance instead of general business knowledge. However, there was no choice of courses for him in the first year of study, which diminished his level of motivation. It is reasonable to argue that students should have breadth as well as depth; therefore, the curriculum design was sensible. Curriculum design inevitably involves decisions about finding an acceptable balance between opposing tensions, such as providing students with a breadth of knowledge and allowing freedom of choice to maximise interest. There are also, of course, resource considerations in providing a range of choice: 
Every BBA student took the same subjects in the first year. I couldn't sense the difference. We only got one subject that was related to our option. ...I am more interested in the core subject. I think I can learn the business knowledge from books. (BUSS)

The chemistry student chose courses so that interests could be followed. However, he did observe that some other students were more concerned about which courses were most likely to result in good grades:

Some students will study according to their grades, such as which subjects will enable them to obtain good grades. I think one's interest is equally important...I will choose according to my own interest. (CHEM)

\section{Establishing relevance}

Establishing relevance was related to creating interest, in that demonstrating relevance was a prime way to promote interest. Relevance could be shown by giving an application of a theory. The relevance of material could be shown by relating it to real-life examples, to current topics or to local applications (Kember and McNaught 2007).

The chemistry students wanted to know how the chemicals and their reactions were used in everyday application. The relevance of the discipline can be shown through application in doing practical experiments. Establishing relevance made the discipline meaningful to the chemistry students, which enhanced their level of motivation:

I think it is important to relate chemistry to daily life and that it has to be applicable to our daily life. (CHEM3)

Theory needed to be put in context by showing application. This meant that there needed to be examples showing the application of theory. (CHEM)

If we can have more examples, that would be better. (CHEM1)

The same principle applied to the business degree. Because business is an applied subject, it should not be hard to find current events which can exemplify important constructs:

Good teachers apply lots of theories into cases. Teacher talk is not the only option for their classes. We have interaction between us. Sometimes, we have to discuss after viewing the newspaper cuttings. Sometimes, videos will be shown to us. Also I have told you about having guest speakers on special topics. For our course, we have to observe and notice what happens around us. We are not only learning how to be a good marketer, but also learning from exemplars of the field. (BUSS4)

\section{Professional relevance}

The business students' courses were able to establish relevance to the profession. His expectation was expressed in terms of the applicability of knowledge in the future professional role. This principle applied to other professional fields too. Students entering professional programs clearly expected to be prepared for their future profession and, therefore, expected their courses to be relevant to this need. This was a way in which career expectations could be used as a strong positive motivational influence: 
This course will provide me with some understanding of the real business world. I have to learn the operational procedures in the business field. I expect the knowledge

I learn here can be used at work in this sense. (BUSS)

Teachers of professional programs, therefore, had an opportunity to motivate their students through showing how what was taught could be relevant to a future career in the professional field. When theory was taught, there could be an opportunity to establish its relevance by showing how it could be applied in practice by professionals in the field.

This opportunity, however, provided a double-edged sword effect. Students expected professional programs to prepare them for a career in the profession. If they could not see how material taught in a program served that purpose, they could easily lose motivation.

\section{Building block curriculum}

The antithesis of establishing relevance was teaching abstract theory. This seemed to happen all too often, because the most common curriculum design model seemed to be the traditional building block design in which the initial parts of a program are dedicated to basic theory. This often includes subjects other than the subject major. These could be essential prerequisite knowledge related to the major, but if relevance is not established, students do not realise this. This seemed to be the case all too often as the subjects were usually taught as pure theory by specialists in the area without making an attempt to show relevance to the major.

The building block curriculum seemed to be particularly problematic in professional programs. Students often selected these in order to escape from the pure subjects studied at school, yet they found that much of the initial part of their curriculum consisted of theoretical subjects which, in their view, did not clearly relate to the professional field that they had chosen. The dilemma was not helped by many students in professional programs having remarkably limited ideas about their intended profession.

There were some suggestions and examples of curriculum designs which could alleviate the problem. Students found it valuable if there was an initial course which provided a road-map showing how constituent knowledge taught in early courses was utilised in later ones. In professional programs, there was value in having an early period of exposure to professional practice. In these periods, the students acted largely as an observer to learn how professionals in the field performed and the sorts of knowledge needed to be an effective professional.

\section{Learning activities}

Motivation also came through being involved in learning activities. Reflecting on the whole set of interviews, a wide range of types of active learning was mentioned. A distinction came out clearly. Students commonly contrasted sitting passively in lectures, which was generally uninspiring, to being engaged in learning activities. These ranged in the degree of motivation that they afforded, but purely didactic courses should clearly be eschewed.

For the business program, it was common for students to work in groups doing projects or giving presentations. The following quotation from the business student describes his best experience of doing group work. He enjoyed the project in which he was required to work in a group of students majoring in different professional studies. He anticipated that 
such experiences would be useful for future work, because most businesses function as multi-disciplinary teams:

The subject is called Strategic Management. We form a group with students from different professional studies. Everybody has to contribute what they have got from their professional studies. This is really necessary for us to work in groups. I think this is common for us to work in a similar way in the future. I really appreciate such kinds of group work. (BUSS)

There was a relationship to the previous facet of relevance. Because the group project was seen as highly relevant to future career needs, it was highly motivating. In the beginning, though, the business student was not motivated by his individual research project. He regarded the work as meaningless until he talked with his supervisor, who clarified the purpose of the activity:

To be frank, I don't think it is possible for us to really conduct research individually. What we are doing now is copying from different sources. It is not easy for us to do a creative or innovative research project. I can't deny that our research is not up to standard. However, my supervisor told me that there is a chance for me to practice and learn what research is. This is a trial only. When I view things from his perspective, I find it meaningful and useful for me. At least, I have learned how to read journal articles and theses and to develop an interest. (BUSS)

Perceived relevance also influenced the chemistry students' perceptions of the motivating influence of types of activities. The interest in experimental work has already become clear. On the other hand, a non-experimental project was not seen as authentic and thus became a task to be completed:

We have done one project and that was...like researching on cosmetics to see their chemical content. We strolled through supermarkets and took some photos, but it was impossible for us to take home samples and analyse them. We were 'discussing war tactics on paper', because we couldn't do much, and all we did was to copy what's written at the back regarding their chemical components, find some books, and draw out their structure. (CHEM)

\section{Teaching for understanding}

The chemistry student rated lecturers in terms of their ability to help students to understand the constructs that they were trying to teach. The worst were those who could not be understood at all: “And there are some teachers whose path of thinking we just can't follow, and who have no clue as to how we can get about studying the course. I am not used to such teaching at all" (CHEM). Others gave a mass of materials and left students to work out what were the key constructs: "Some would lecture almost everything to us, told us to study their notes" (CHEM). Better teachers provided a road map to show how material fitted together. These better teachers identified the key concepts: "Some were secondary teachers who gave me a sense of security because they could provide a clear direction for us and would direct certain parts for us to study" (CHEM). Still other teachers restricted their lecturing. They recognised the principle of learning through doing. A more thorough understanding can come through a degree of self-direction in learning: "Some like to give minor lectures, wanting us to search things on our own, do things on our own, think on our own" (CHEM). 
An aid to understanding was the degree of coordination between lectures and laboratories. The curriculum seemed to have been well enough designed so that the laboratory experiments could help understanding of the material introduced in the lectures: "In addition, we have to do experiments for organic and inorganic chemistry, which are quite impressive for me and helpful in terms of my understanding of lectures" (CHEM). The students in the business degree also thought that promoting understanding was a hallmark of a good teacher. It was linked to showing relevance also: "Some professors are very skilful in inspiring students with controversial issues or they can explain clearly that enables you to understand the whole mechanism" (BUSS1).

The concept of teaching for understanding can be seen as related to encouraging students to employ a deep approach to learning. There is an extensive literature on contextual influences upon approaches to learning (e.g. Marton et al. 2005; Prosser and Trigwell 1999; Richardson 2000). Aligning curricula to produce teaching and learning environments conducive to a deep approach has become a prominent approach to educational development and quality assurance (e.g. Biggs and Tang 2007; Ramsden 1992).

\section{Assessment of learning activities}

Students are assessment driven (Biggs and Tang 2007; Kember and McNaught 2007). Students concentrate their time and attention on what they perceive will result in higher grades for them. Therefore, it was important that the assessment was consistent with the three previous motivating factors. This meant that the assessment needed to test understanding, award marks for learning activities, and test the application of theory to relevant practical applications. The business student recognised that this reinforced the need for a balance between the assessment components:

If the mid-term test contributes about $30 \%$ to the final grade and $40 \%$ for the final exam and another $30 \%$ for assignments or other tasks, you can see a balance in examining our performance from the beginning until the end. (BUSS)

If there was a concern, it was that there was too much emphasis on tests and examinations which tested recall rather than understanding. As many students have recognised, poorly designed examinations can reduce incentives to concentrate on understanding material. Instead, the concentration is upon remembering what is likely to be in the test paper:

The exam is testing students' learning. If there is overemphasis on exams, students tend to recite and memorise useful bits in order to fit in the exam requirements. I think that an exam may not be able to show the actual gain and capability of students in different subjects. (BUSS)

Another concern on assessment was expressed by the chemistry student. He showed his concern that assessment with a heavy weighting on examinations did not provide feedback. Because examinations were at the end, they did not provide feedback during the course. It also seemed common not to return marked papers; so the only feedback was a mark, which did not reveal strengths and weaknesses. Without knowing how well they performed on particular questions, students cannot understand how to improve their results. This concern was not unique to the chemistry student, as a total of seven students commented upon receiving insufficient feedback: "For exams, we don't get to see our results. When we are both answering the same amount of things, how come your grade gets to be higher than mine?" (CHEM). 
Close teacher-student relationships

Generally, three important aspects for the establishment of close teacher-student relationships could be identified from the interviews. They were availability, friendliness and helpfulness. Teachers possessing these three qualities were more successful in establishing close and helpful relationships with students.

Unless the teachers showed that they were approachable, students were reluctant to ask for help with material or tasks that they found difficult. Therefore, close teacher-student relationships had a positive influence on the motivation of students in their learning. Teacher-student relationships for the business student were quite good. The business student was willing to contact most of his teachers by going to their offices or sending them emails when he was in need of help: "I don't find any problems communicating with my professors. We always chat and I am willing to express my view" (BUSS).

Again there was a range, particularly the degree of approachability this time. Those teachers who showed themselves to be approachable and available were the ones whom students contacted:

Some professors are more willing to contact us. ...We tend to contact or stay with those friendly professors. ...If the professors are mean and serious, we dare not go to their office for a casual talk. Some professors are always out of the office. It's a bit difficult to find them. (BUSS)

The chemistry student also observed a range in the degree of approachability of his teachers. On average, though, the chemistry teachers were less approachable than the business teachers:

In fact, most of them are nice, but I don't think a lot of us will ask them for help. If s/ he is not in a very bad mood, s/he is willing to answer our questions. ...Some professors are just like my boss, like they are in a bad mood. ...I don't think that would ever happen at secondary school. ... Our professors are more like the weather, forever changing. This is what we think. (CHEM)

\section{Sense of belonging between classmates}

Sense of belonging was more likely to develop if students keep together as a class cohort for a substantial part of their degree. This was quite common in the sample of programs, as it is common in Hong Kong for students to enter specified major streams with a restricted range of options.

This facet could then be in tension with stimulating interest through offering a free and wide range of choice of courses. The wider the choice, the less students stay together as a cohort, thus minimising the chance of class coherence developing. As with many issues in curriculum design, it is necessary to find an intelligent point of balance between conflicting demands.

The business cohort had established a sense of belonging between classmates. The business student believed that this resulted from the small size of the class. This is certainly a helpful factor, but is not the only important variable, as other small class groups did not have such good relationships among the students: "The class size of my option is not large. There are about 40 students only. As a result, we have quite a close relationship" (BUSS). A sense of belonging also develops through a class being assigned group activities that promote relationships among the cohort (Yan and Kember 2003, 2004a, b): “A relationship 
is built up through cooperation rather than having classes together. For example, we have to overcome a common problem which in return ends up with a friendship at last" (BUSS).

By contrast, the chemistry class was more splintered, even though the class size was not that much bigger and the range of options was quite restricted. The didactic style of teaching and the heavy reliance on tests and examinations did little to promote interaction among the class. The low level of teacher-student interaction also did not promote student-student relationships:

I am close with one or two of them, but I seldom share my private thoughts with them. ...Most of us talk about things happening around us or within our academic realm, rarely will we talk about my or their personal thoughts. (CHEM)

\section{Conclusion}

There are academics who consider motivation to be a function of the student. While individual differences are important, this study makes it clear that teachers have a major impact on the level of motivation of their students.

The motivation of students was found to be affected by a broadly based teaching and learning environment, characterised by the following eight principal elements.

- Establishing interest

- Allowing choice of courses

- Establishing relevance

- Learning activities

- Teaching for understanding

- Assessment of learning activities

- Close teacher-student relationships

- Sense of belonging between classmates.

The level of interest was strongly linked to motivation. Students choose to study a particular subject because they feel that it is consistent with their interests. Therefore, it can help to have a reasonably wide choice of courses to offer so that individuals can select combinations of courses which are of interest to them.

Once courses are selected, the students then expect their teachers to do their best to enhance interest. One of the principal ways in which this could be accomplished was by establishing the relevance of what was taught. Relevance could be shown by relating theory to practical applications, to local examples, to current issues or to everyday applications. In professional programs, relevance could be established through courses which prepared students well for their eventual profession. Career preparation was seen by students as a positive motivating force and not as an extrinsic de-motivator.

Students reported that motivation could be enhanced through appropriate learning activities. Teaching for understanding was an important component of a motivating environment. As students are assessment driven, it was important for assessment tasks to be consistent with the other elements of the environment.

The final two elements in motivating teaching and learning environments were the social interaction elements of good teacher-student and student-student relationships. Students wanted to feel that their teachers were approachable so that they could ask for advice and help when necessary. Coherent classes with a strong sense of belonging were a motivating influence. It was possible for teachers to promote coherence through setting activities which encouraged discussion and required group work. 
The inclusion of the social element in the motivational learning environment meant that the scope was broader than the way in which curricula are often envisaged in higher education. Using the cases to illustrate the elements of the environment, we believe, has shown that they act in concert and tend to reinforce each other. To motivate student learning, therefore, it is necessary to take a holistic view of the teaching and learning environment which students experience.

Acknowledgments The work described in this article was fully supported by a grant from the Research Grants Council of the Hong Kong Special Administrative Region (Project no. CYUHK4104/04H).

\section{References}

Ames, C. (1992). Classrooms: Goals, structures, and student motivation. Journal of Educational Psychology, 84, 261-271.

Beaty, L., Gibbs, G., \& Morgan, A. (2005). Learning orientations and study contracts. In F. Marton, D. Hounsell, \& N. Entwistle (Eds.), The experience of learning: Implications for teaching and studying in higher education (3rd ed., pp. 72-86). Edinburgh, UK: University of Edinburgh, Centre for Teaching, Learning and Assessment. [Internet].

Biggs, J. (1987). Student approaches to learning and studying. Melbourne, Australia: Australian Council for Educational Research.

Biggs, J., \& Tang, C. (2007). Teaching for quality learning at university (3rd ed.). Buckingham, UK: Society for Research in Higher Education and The Open University Press.

Elliot, A., \& McGregor, H. (2001). A $2 \times 2$ achievement goal framework. Journal of Personality and Social Psychology, 80, 501-519.

Glaser, B. G., \& Strauss, A. L. (1967). The discovery of grounded theory. Chicago: Aldine.

Hsu, F. L. K. (1981). Americans and Chinese: Passage to differences (3rd ed.). Honolulu, HI: University of Hawaii Press.

Kember, D. (1995). Open learning courses for adults: A model of student progress. Englewood Cliffs, NJ: Educational Technology Publications.

Kember, D., Hong, C., \& Ho, A. (2008). Characterising the motivational orientation of students in higher education: A naturalistic study in three Hong Kong universities. British Journal of Educational Psychology, 78, 313-329.

Kember, D., \& McNaught, C. (2007). Enhancing university teaching: Lessons from research into award winning teachers. Abingdon, UK: Routledge.

Lincoln, Y., \& Guber, E. (1985). Naturalistic inquiry. Newbury Park, CA: Sage Publication.

Marton, F., Hounsell, D., \& Entwistle, N. (Eds.). (2005). The experience of learning: Implications for teaching and studying in higher education (3rd ed.). Edinburgh, UK: University of Edinburgh, Centre for Teaching, Learning and Assessment. [Internet].

NVivo Qualitative Data Analysis Program (Version 1.3) [Computer software]. (2000). Melbourne, Australia: QSR International.

Pintrich, P. R. (2003). Multiple goals and multiple pathways in the development of motivation and selfregulation. Development and motivation, 1(1), 137-153. (BJEP Monograph Series II, Number 2).

Pintrich, P., \& Schunk, D. (2002). Motivation in education. Upper Saddle River, NJ: Prentice-Hall Merrill.

Prosser, M., \& Trigwell, K. (1999). Understanding learning and teaching: The experience in higher education. Buckingham, UK: SRHE and Open University Press.

Ramsden, P. (1992). Learning to teach in higher education. London: Routledge.

Richardson, J. T. E. (2000). Researching student learning: Approaches to studying in campus-based and distance education. Buckingham, UK: SRHE and Open University Press.

Salili, F. (1996). Accepting personal responsibility for learning. In D. Watkins \& J. B. Biggs (Eds.), The Chinese learner: Cultural, psychological and contextual influences (pp. 85-106). Melbourne, Australia and Hong Kong: Australian Council for Educational Research and the Comparative Education Research Centre, University of Hong Kong.

Taylor, L., Morgan, A., \& Gibbs, G. (1981). The “orientation” of Open University foundation students to their studies. Teaching at a Distance, 20, 3-12.

University Grants Committee of Hong Kong. (2003). Facts and figures 2002. Hong Kong: University Grants Committee Secretariat. Retrieved November 20, 2005, from http://www.ugc.edu.hk/english/documents/ figures/. 
Yan, L., \& Kember, D. (2003). The influence of the curriculum and learning environment on the learning approaches of groups of students outside the classroom. Learning Environments Research, 6, 285-307.

Yan, L., \& Kember, D. (2004a). Avoider and engager approaches by out-of-class groups: The group equivalent to individual learning approaches. Learning and Instruction, 14(1), $27-49$.

Yan, L., \& Kember, D. (2004b). Engager and avoider behavior in types of activities performed by out-ofclass learning groups. Higher Education, 48, 419-438.

Yang, K. S., \& Yu, A. B. (1988). Social- and individual-oriented achievement motivation: Conceptualization and measurement. Paper presented at the Symposium on Chinese Personality and Social Psychology, 24th International Congress of Psychology, Sydney, Australia.

Yu, E. S. H. (1974). Achievement motive, familism and hsiao: A replication of McClelland-Winterbottom studies. Unpublished doctoral dissertation, University of Notre Dame, USA.

Yu, A. B. (1996). Ultimate life concerns, self, and Chinese achievement motivation. In M. H. Bond (Ed.), The handbook of Chinese psychology (pp. 227-246). Oxford, UK: Oxford University Press. 